\title{
Bronchial Aspiration of Capsule Endoscope
}

\author{
Matthieu Buscot ${ }^{\mathrm{a}}$ Sylvie Leroy ${ }^{\mathrm{a}}$ Johanna Pradelli ${ }^{\mathrm{a}}$ Nouha Chaabane ${ }^{\mathrm{a}}$ \\ Xavier Hebuterne $^{b}$ Charles-Hugo Marquette ${ }^{a, c}$ Jerôme Filippi ${ }^{b}$ \\ a Service de Pneumologie and b Service de Gastro-Entérologie et Nutrition, Centre Hospitalier Universitaire, \\ Université Nice Sophia Antipolis, and 'FHU OncoAge, Côte d'Azur University, Nice, France
}

\section{Established Facts}

- Video capsule aspiration is a potentially life-threatening complication that has been reported with increasing frequency.

- A rapid diagnosis can be made thanks to live transmission of the images from the capsule.

- Rigid bronchoscopy remains the safest method of extraction.

\section{Novel Insights}

- We report capsule extraction and gastrointestinal repositioning during the same procedure.

- This allows safe and successful digestive exploration without additional gastrointestinal endoscopy of patients who accidentally aspirated the capsule.

\section{Key Words}

Capsule endoscope · Complications · Bronchoscopy

\section{Abstract}

Capsule endoscope aspiration is an increasingly reported complication, potentially responsible for respiratory distress and asphyxia. This adverse event is primarily managed by rigid bronchoscopy when spontaneous expulsion does not occur. This complication is all the more detrimental to patients as it can delay or jeopardize further digestive exploration. We report direct repositioning of the capsule in the stomach at the same time as bronchoscopy, thus making second-line gastrointestinal endoscopy needless.

(c) 2017 S. Karger AG, Basel

\section{Introduction}

Over the past decades, capsule endoscopy has become a routine tool in the exploration of occult gastrointestinal (GI) bleeding after a non-diagnostic upper GI endoscopy and colonoscopy. The most frequent complication of capsule endoscopy is retention in the digestive tract, which occurs in 1-5\% of cases. Bronchial aspiration of the capsule is a complication that has been increasingly reported. Although potentially responsible for acute respiratory distress, no fatality has been reported as yet. The method of choice for extraction of the capsule is rigid bronchoscopy with the use of a foreign body retrieval net or basket.

\section{KARGER}

(C) 2017 S. Karger AG, Basel

E-Mail karger@karger.com

www.karger.com/res
Matthieu Buscot

CHU de Nice, Hôpital Pasteur

30 , avenue de la voie romaine

FR-06100 Nice (France)

E-Mail buscot.m@chu-nice.fr 
Fig. 1. Picture of the bronchial tree transmitted by the capsule.

Fig. 2. Chest X-ray performed just after aspiration showing the capsule at the entrance of the left main bronchus.
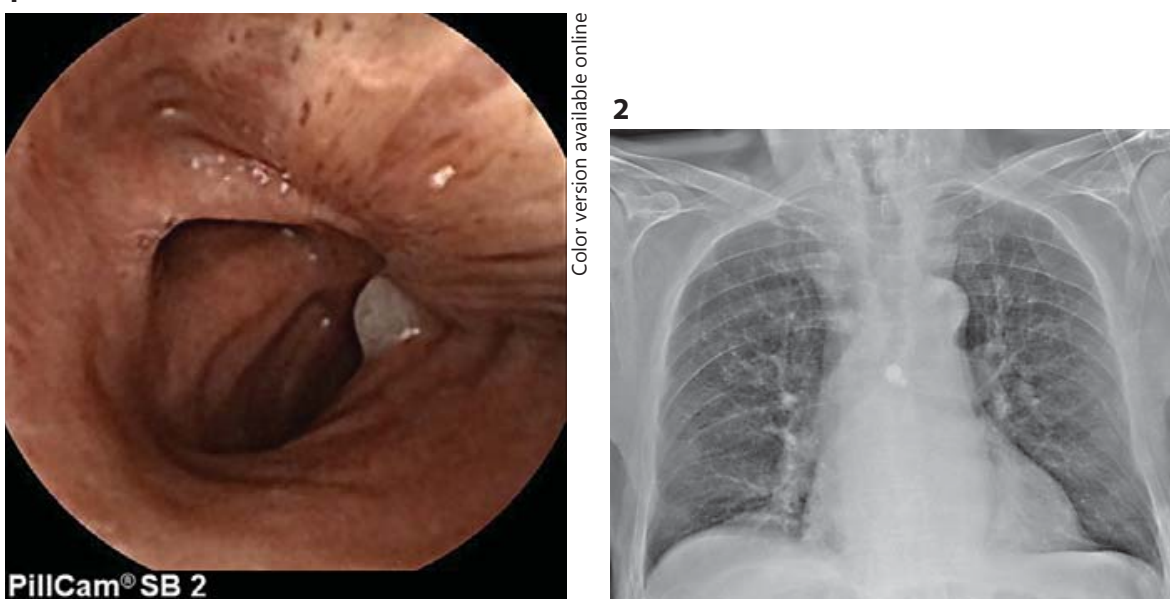

Table 1. Cases of reported capsule endoscope aspiration and the outcome regarding subsequent digestive exploration (adapted from Lucendo et al. [1] and Koulaouzidis et al. [2])

\begin{tabular}{|c|c|c|c|c|c|c|c|}
\hline First author [ref.], year & $\begin{array}{l}\text { Age, } \\
\text { years/ } \\
\text { gender }\end{array}$ & $\begin{array}{l}\text { History of } \\
\text { swallowing } \\
\text { disorders }\end{array}$ & $\begin{array}{l}\text { Acute } \\
\text { presen- } \\
\text { tation }\end{array}$ & $\begin{array}{l}\text { Favorable } \\
\text { outcome }\end{array}$ & Mode of extraction & $\begin{array}{l}\text { Subsequent } \\
\text { GI video- } \\
\text { exploration }\end{array}$ & $\begin{array}{l}\text { Mode of subse- } \\
\text { quent insertion of } \\
\text { the capsule in the GI } \\
\text { tract }\end{array}$ \\
\hline Schneider [see ref. 1], 2003 & $64 / ?$ & no & yes & yes & spontaneous & yes & none \\
\hline Sinn [see ref. 1], 2004 & $69 / \mathrm{f}$ & no & yes & yes & spontaneous & yes & none \\
\hline Tabib [see ref. 1], 2004 & $87 / \mathrm{m}$ & no & yes & yes & rigid bronchoscopy & ? & ? \\
\hline Buchkremer [see ref. 1], 2004 & $74 / \mathrm{m}$ & no & no & yes & flexible bronchoscopy & $?$ & $?$ \\
\hline Rondonotti [see ref. 1], 2005 & $? / ?$ & no & no & yes & spontaneous & $?$ & $?$ \\
\hline Shiff [see ref. 1], 2007 & $67 / \mathrm{m}$ & yes & yes & yes & rigid bronchoscopy & ? & ? \\
\hline Nathan [see ref. 1], 2007 & $93 / \mathrm{m}$ & no & no & yes & spontaneous & yes & none \\
\hline Sepehr [see ref. 1], 2007 & $67 / \mathrm{m}$ & yes & yes & yes & rigid bronchoscopy & ? & ? \\
\hline Guy [see ref. 1], 2009 & $90 / \mathrm{m}$ & no & no & yes & rigid bronchoscopy & no & none \\
\hline Leeds [see ref. 1], 2009 & $85 / \mathrm{m}$ & no & no & yes & spontaneous & $?$ & $?$ \\
\hline Bredenoord [see ref. 1], 2009 & $65 / \mathrm{m}$ & $?$ & yes & yes & spontaneous & yes & none \\
\hline Choi [see ref. 1], 2010 & $75 / \mathrm{m}$ & no & no & yes & rigid bronchoscopy & $?$ & $?$ \\
\hline Depriest [see ref. 1], 2010 & $90 / \mathrm{m}$ & no & no & yes & rigid bronchoscopy & yes & $?$ \\
\hline Kurtz [see ref. 1], 2010 & $73 / \mathrm{m}$ & no & yes & yes & rigid bronchoscopy & $?$ & $?$ \\
\hline Lucendo [1], 2011 & $80 / \mathrm{m}$ & no & yes & yes & spontaneous & yes & none \\
\hline Koulaouzidis [2], 2011 & $76 / \mathrm{m}$ & $?$ & no & yes & spontaneous & yes & none \\
\hline Pezzoli [3], 2011 & $82 / \mathrm{m}$ & no & no & yes & spontaneous & yes & none \\
\hline Degani [4], 2011 & $74 / \mathrm{m}$ & no & no & yes & rigid bronchoscopy & & \\
\hline Borman [5], 2011 & $84 / \mathrm{m}$ & no & yes & yes & rigid bronchoscopy & $?$ & $?$ \\
\hline Girdhar [6], 2012 & $83 / \mathrm{m}$ & no & no & yes & rigid bronchoscopy & $?$ & $?$ \\
\hline \multirow[t]{3}{*}{ Despott [13], 2012} & $65 / \mathrm{m}$ & no & no & yes & rigid bronchoscopy & yes & same endoscopy \\
\hline & $\overline{73 / \mathrm{m}}$ & no & no & yes & flexible bronchoscopy & yes & $\begin{array}{l}\text { subsequent } \\
\text { endoscopy }\end{array}$ \\
\hline & $\overline{81 / \mathrm{m}}$ & no & no & yes & rigid bronchoscopy & $?$ & $?$ \\
\hline Parker [7], 2012 & $77 / \mathrm{f}$ & no & yes & no & spontaneous & yes & $\begin{array}{l}\text { subsequent } \\
\text { endoscopy }\end{array}$ \\
\hline Singh [8], 2013 & $56 / \mathrm{m}$ & no & no & yes & rigid bronchoscopy & $?$ & $?$ \\
\hline Pereira [9], 2013 & $78 / \mathrm{m}$ & no & yes & yes & spontaneous & yes & none \\
\hline \multirow[t]{2}{*}{ Ding [10], 2013} & $80 / \mathrm{m}$ & no & yes & yes & spontaneous & $?$ & $?$ \\
\hline & $\overline{88 / \mathrm{m}}$ & no & yes & yes & spontaneous & yes & none \\
\hline Mannami [11], 2015 & $85 / \mathrm{m}$ & no & no & yes & spontaneous & yes & none \\
\hline Juanmartiñena Fernández [12], 2016 & $82 / \mathrm{m}$ & no & no & yes & spontaneous & yes & none \\
\hline
\end{tabular}

?, not reported in the publication; GI, gastrointestinal.

Bronchial Aspiration of Capsule Endoscope 
Little is known about the outcome of patients regarding their further GI workup. Some patients undergo a secondline gastroscopy in order to place the capsule directly in the stomach or duodenum. This means that patients have to undergo repeated general anesthesia (GA), which is challenging in elderly patients with poor health. There is even a probability that digestive explorations are abandoned following aspiration, considering the unfavorable risk-benefit balance of a subsequent GA for capsule placement.

\section{Case Report}

A 74-year-old man with a medical history of ischemic stroke and chronic obstructive pulmonary disease, without an overt swallowing disorder, was referred to our center for iron deficiency anemia exploration. The upper GI endoscopy and the colonoscopy did not show any source of bleeding. Small-intestine exploration by capsule endoscopy was planned. No underlying neurological or swallowing disorder was detected, and the capsule (PillCam ${ }^{\circledR} \mathrm{SB} 2$, USA) was ingested by the conscious patient without sedative premedication. Shortly after, the patient presented with a typical choking episode with mild respiratory distress with bouts of coughing and oxygen desaturation. Direct visualization of the images from the capsule confirmed its presence in the respiratory tract. The images showed the proximal lumen of a bronchial tree, with typical collapse at the end of expiration. Slight movements of the capsule were observed during coughing and expiration and showed the entrance of the left main bronchus and the main carina (Fig. 1 and online suppl. Video 1; for all online suppl. material, see www.karger.com/doi/10.1159/000453587). The chest Xray performed quickly afterwards (Fig. 2) showed the capsule located in the left main bronchus.

A rigid bronchoscopy under GA was immediately performed and confirmed the presence of the capsule in the left main bronchus. The capsule was retrieved with a foreign body basket (Zero Tip $^{\mathrm{TM}}$, Boston Scientific ${ }^{\circledR}$, USA). The bronchoscope was then immediately introduced into the lower esophagus allowing direct repositioning of the capsule into the GI tract with peanut foreign body forceps. The respiratory outcome was uneventful. Subsequent small-bowel exploration could then be performed and showed duodenal and jejunal angiomas.

\section{Discussion}

Device aspiration is a potentially life-threatening and increasingly reported complication of capsule endoscopy. It is estimated to happen in about $1 / 1,000$ cases. A thorough review of cases reported in the literature (Table 1) shows that this complication occurs primarily in older males without a history of swallowing disorders [113]. Most of the time, aspiration remains asymptomatic, and the diagnosis is made a posteriori with spontaneous return of the capsule into the digestive tract.
Information regarding the outcome of digestive explorations remains scarce in reported cases. This underscores the fact that these patients may have a delayed or abandoned digestive workup following capsule aspiration.

In our case, the patient did not report any previous swallowing disorder, as in most of the reported cases. Nevertheless, several factors could explain the aspiration of the capsule, such as age (presbyphagia) combined with the small size and low weight of the device $(<4 \mathrm{~g}, 11 \times 26$ $\mathrm{mm}$ ). Moreover, a latent cerebrovascular disease could not be excluded since our patient was a former smoker and suffered from peripheral artery disease.

We demonstrated the feasibility and the success of GI capsule repositioning right after bronchoscopy when the patient was under GA. This procedure has only been reported once by Despott et al. [13] in 2012, but no information regarding the outcome of the digestive exploration was given. We consider that this option should be chosen for all patients undergoing bronchoscopic extraction of a video capsule under GA. This option avoids subsequent endoscopy and GA of the patient and allows a prompt and complete digestive workup of patients who are often in poor medical condition.

\section{Financial Disclosure and Conflicts of Interest}

The authors report no biomedical financial interests or potential conflicts of interest relevant to this article.

\section{References}

Lucendo AJ, González-Castillo S, FernándezFuente M, Rezende LC: Tracheal aspiration of a capsule endoscope: a new case report and literature compilation of an increasingly reported complication. Dig Dis Sci 2011;56: 2758-2762.

2 Koulaouzidis A, Douglas S, Plevris JN: Tracheal aspiration of capsule endoscopes: completing a cases compilation. Dig Dis Sci 2011; 56:3101-3102.

3 Pezzoli A, Fusetti N, Carella A, Gullini S: Asymptomatic bronchial aspiration and prolonged retention of a capsule endoscope: a case report. J Med Case Reports 2011;5:1-3.

4 Degani AT, Forseen CJ, Chang ASY: Severe hypoxia following video capsule endoscopy. Chest Dis Rep 2011;1:29-30.

5 Borman JJ, Hilbelink RT: Video endoscope aspiration. Appl Radiol 2011;40:37-38.

6 Girdhar A, Usman F, Bajwa A: Aspiration of capsule endoscope and successful bronchoscopic extraction. J Bronchology Interv Pulmonol 2012;19:328-331. 
7 Parker C, Davison C, Panter S: Tracheal aspiration of a capsule endoscope: not always a benign event. Dig Dis Sci 2012;57:1727-1728.

8 Singh RA, Pai KR, Satur CMR: Delayed presentation of an aspirated capsule endoscope. J Surg Case Rep 2013;2013:rjt082.

9 Pereira B, Santos A, Leitao C, Banhudo A: Aspiration of capsule endoscope. Rev Esp Enfermedades Dig 2013;105:438-439.
10 Ding N, Hair C, De Cruz P, Watson J: Education and imaging. Gastrointestinal: symptomatic bronchial aspiration of capsule endoscope - a significant complication. J Gastroenterol Hepatol 2013;28:761.

11 Mannami T, Ikeda G, Seno S, Sonobe H, Fujiwara N, Komoda M, et al: Capsule endoscope aspiration after repeated attempts for ingesting a patency capsule. Case Rep Gastroenterol 2015;9:347-352.
12 Juanmartiñena Fernández JF, FernándezUrien I, Vila Costas JJ: Asymptomatic bronchial aspiration of capsule endoscope: a significant complication. Rev Esp Enfermedades Dig 2016;108:605.

13 Despott EJ, O’Rourke A, Anikin V, Davison C, Panter S, Bromley J, et al: Tracheal aspiration of capsule endoscopes: detection, management, and susceptibility. Dig Dis Sci 2012; 57:1973-1974. 